\title{
Does additional antimicrobial treatment have a better effect on URTI cough resolution than homeopathic symptomatic therapy alone? A real-life preliminary observational study in a pediatric population
}

Alessandro Zanasi $i^{*}$, Salvatore Cazzato ${ }^{2}$, Massimiliano Mazzolini ${ }^{3}$, Carla Maria Sofia lerna ${ }^{3}$, Marianna Mastroroberto ${ }^{4}$, Elena $\mathrm{Nardi}^{4}$ and Antonio Maria Morselli-Labate ${ }^{4}$

\begin{abstract}
Background: The effectiveness of a homeopathic syrup on cough has been demonstrated in an adult population in a previous double-blind randomized study. The present prospective observational study investigated children affected by wet acute cough caused by non-complicated URTIs, comparing those who received the homeopathic syrup versus those treated with the homeopathic syrup plus antibiotic.

Objectives: The aims were: 1) to assess whether the addition of antibiotics to a symptomatic treatment had a role in reducing the severity and duration of acute cough in a pediatric population, as well as in improving cough resolution; 2) to verify the safety of the two treatments.

Methods: Eighty-five children were enrolled in an open study: 46 children received homeopathic syrup alone for 10 days and 39 children received homeopathic syrup for 10 days plus oral antibiotic treatment (amoxicillin/clavulanate, clarithromycin, and erythromycin) for 7 days. To assess cough severity we used a subjective verbal categorydescriptive (VCD) scale.
\end{abstract}

Results: Cough VCD score was significantly $(P<0.001)$ reduced in both groups starting from the second day of treatment $(-0.52 \pm 0.66$ in the homeopathic syrup group and $-0.56 \pm 0.55$ in children receiving homeopathic syrup plus oral antibiotic treatment). No significant differences in cough severity or resolution were found between the two groups of children in any of the 28 days of the study. After the first week (day 8) cough was completely resolved in more than one-half of patients in both groups. Two children (4.3\%) reported adverse effects in the group treated with the homeopathic syrup alone, versus 9 children (23.1\%) in the group treated with the homeopathic syrup plus antibiotics $(P=0.020)$.

Conclusions: Our data confirm that the homeopathic treatment in question has potential benefits for cough in children as well, and highlight the strong safety profile of this treatment. Additional antibiotic prescription was not associated with a greater cough reduction, and presented more adverse events than the homeopathic syrup alone.

Keywords: Anti-bacterial agents, Antitussive agents, Cough, Homeopathy, Respiratory tract infections

\footnotetext{
* Correspondence: alessandro.zanasi@aosp.bo.it

${ }^{1}$ Italian Association for Cough Study (AIST), Via Mazzini, 12, 40138 Bologna, Italy

Full list of author information is available at the end of the article
} 


\section{Background}

Acute cough is a very common problem for children; the majority of them have up to five viral upper respiratory tract infections (URTIs) with cough every year [1], usually self-limiting within 3 weeks $[2,3]$. Generally, such frequency of cough is more applicable to young children than to childhood and adolescence $[2,3]$. Acute cough in children may last over 20 days and become worrying for the young patients and their parents [4-6]. Symptomatic treatment is often prescribed after a medical consultation, although its effectiveness it is still a matter of debate [7-9], and - contrary to recommendations - antibiotics are frequently administered to children with acute persistent cough [10-13].

A survey in the United States found that antibiotics were prescribed to $44 \%$ of patients with common cold, to $46 \%$ with upper respiratory tract infections and to $75 \%$ with bronchitis. Children aged 0 to four years received $53 \%$ of all antibiotics prescribed to the pediatric population [14].

A Cochrane review of antibiotic use for cough and common cold concluded that there was not enough evidence of important benefits in the treatment of URTI, whereas there was a significant increase in adverse effects associated with antibiotic use [15].

However, parents are rarely satisfied with in the watchful approach, and often have an expectation that antibiotics should be prescribed [16]. The aim of this preliminary study was to evaluate if the addition of antibiotics to a symptomatic treatment (homeopathic syrup) improves cough resolution in pediatric patients with acute cough due to uncomplicated URTI.

\section{Methods}

We conducted an open prospective analysis of acute cough visits in four ambulatory settings of pediatric practitioners over a one-year period from December 2013 to December 2014. The study considered only patients affected by wet acute cough caused by noncomplicated URTIs who either received a homeopathic syrup alone (Stodal $200 \mathrm{~mL}$, Boiron SA, Messimy, France) or were treated with the same homeopathic syrup plus antibiotic. The homeopathic syrup was composed of: Anemone pulsatilla $6 \mathrm{CH}$, Rumex crispus 6 $\mathrm{CH}$, Bryonia dioica $3 \mathrm{CH}$, Ipecacuanha $3 \mathrm{CH}$, Spongia tosta $3 \mathrm{CH}$, Sticta pulmonaria $3 \mathrm{CH}$, Antimonium tartaricum $6 \mathrm{CH}$, Myocarde $6 \mathrm{CH}$, Coccus cacti $3 \mathrm{CH}$, Drosera MT. The effectiveness of this homeopathic syrup on cough was investigated in our previous doubleblind randomized study [17]. The syrup's dosage was $5 \mathrm{~mL} 4$ times per day. Choices of antibiotic use, as well as antibiotic type and dosage, were left to the discretion of the physician for each individual patient.

\section{Endpoints}

The first endpoint was to assess whether the addition of antibiotics to a symptomatic treatment had a role in reducing the severity and duration of acute cough in a pediatric population, as well as in improving cough resolution. The second goal was to verify the safety of the two treatments.

\section{Experimental design}

Study assessment was carried out through an analysis of medical records (including patients' history, clinical examination and therapy). All participants filled in a validated standardized pediatric cough diary (verbal category-descriptive scale: VCD) to grade the severity of their cough [18]. The VCD was compiled daily by the patients, assisted by their parents, for 28 consecutive days starting from the first visit. This cough-scoring diary had been previously validated against an objective cough meter measure, and changes in this subjective cough rating were shown to reflect changes in cough counts [18]. The VCD score we used consisted of 6 discrete values: 0 - no cough; 1 - one short period of mild cough without hardship; 2 - some short periods of cough without much hardship; 3 - frequent coughing that does not affect normal daily life or sleep; 4 - serious coughing that is very frequent and interferes with normal daily life or sleep; 5 - distressing continuous coughing that did not stop for $24 \mathrm{~h}$. Cough was considered resolved when a score of less than 2 was reached.

Patients were re-examined at the end of the study and any adverse events were also reported.

\section{Patients}

Eighty-five children were found eligible to be enrolled in the study. Forty-six patients received homeopathic syrup alone for 10 days (Group 1) and thirty-nine children received homeopathic syrup for 10 days plus oral antibiotic treatment (amoxicillin/clavulanate, clarithromycin, and erythromycin) for 7 days (Group 2).

The inclusion criteria were: age between 4 and 15 years, and cough induced by URTIs lasting 5 days or less. Children with pre-existing respiratory problems and/or who had antibiotic treatment or any other medication that might affect the cough symptom within 5 days were excluded from the study.

The baseline characteristics of the two studied groups are shown in Table 1. The two groups proved comparable with respect to sex, age and time from onset of cough. No significant differences in baseline severity of cough were found between male and female patients both in the overall population $(P=0.366)$ and within the two groups $(P=0.719$ in Group 1 and $P=0.322$ in Group 2). 
Table 1 Characteristics of the studied children affected by wet acute cough caused by non-complicated URTI. Data are shown as frequencies or mean \pm standard deviation

\begin{tabular}{|c|c|c|c|}
\hline & $\begin{array}{l}\text { Group 1: Homeopathic } \\
\text { syrup alone }(n=46)\end{array}$ & $\begin{array}{l}\text { Group 2: Homeopathic } \\
\text { syrup plus antibiotic } \\
\text { treatment }(n=39)\end{array}$ & $P$ value \\
\hline Gender: & & & $0.830^{\mathrm{a}}$ \\
\hline Male & 20 (43.5 \%) & 18 (46.2 \%) & \\
\hline Female & 26 (56.5\%) & $21(53.8 \%)$ & \\
\hline Age (years) & $8.2 \pm 2.9$ & $8.5 \pm 2.9$ & $0.674^{b}$ \\
\hline $\begin{array}{l}\text { Time from the onset } \\
\text { of cough (days) }\end{array}$ & $3.9 \pm 1.0$ & $3.8 \pm 0.9$ & $0.785^{b}$ \\
\hline $\begin{array}{l}\text { Verbal category- } \\
\text { descriptive scale at } \\
\text { baseline (VCD) }\end{array}$ & $3.96 \pm 0.73$ & $4.00 \pm 0.65$ & $0.763^{b}$ \\
\hline
\end{tabular}

\section{Ethics}

The research was promoted by the Italian Association for Cough Study (AIST) and was conducted according to the Helsinki declaration. The protocol was approved by the Institutional Review Board and the informed consent was obtained by the legal guardians of the enrolled children.

\section{Sample size and power analysis}

To evaluate sample size, we hypothesized-for this study performed on children-the same results obtained previously in adults after 7 days of administering the same homeopathic syrup [17] (i.e., a difference between groups of VCD equal to 0.7 and a within-group standard deviation of 1.0). Based on these values, we needed to study a total of at least 76 subjects (i.e., 38 subjects in each group, hypothesizing an equal distribution of patients among the two groups) to be able to reject the null hypothesis with probability (power) equal to 0.90 at a significance level of 0.05 . The sample size was estimated by means of the "PS Power and Sample Size Calculations" software (Version 3.0.43; Department of Statistics of the Vanderbilt University, Nashville, TN, USA; http://biostat.mc.vanderbilt.edu/wiki/ Main/PowerSampleSize) according to the Dupont and Plummer procedure $[19,20]$.

\section{Statistical analysis}

Frequencies and mean values \pm standard deviation were used as descriptive statistics. The two groups of children were compared by means of the Fisher's exact and the Kruskal-Wallis tests, while the Wilcoxon matched-pairs signed-rank test was used to test the changes of the VCD

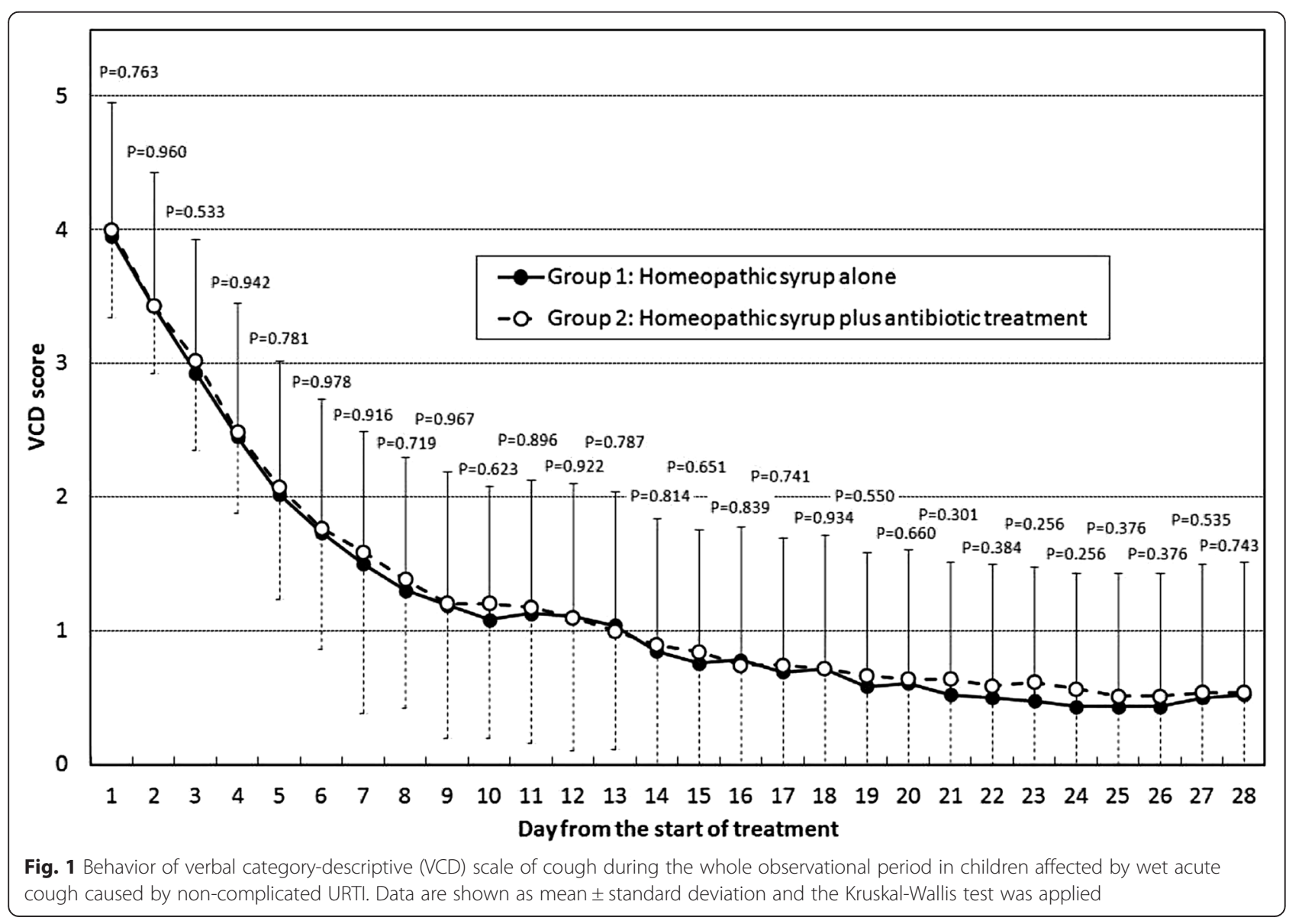


scale observed versus the basal values. The IBM SPSS Statistics package (Version 21; IBM Co., Armonk, NY, USA) was used to analyze the data. Two-tailed $P$ values less than 0.05 were considered statistically significant.

\section{Results Cough severity}

Figure 1 shows the behavior of the verbal categorydescriptive (VCD) scale of cough during the entire observational period. Cough severity was comparable between the two groups at baseline (Day 1; $P=0.763$ ) as well as on all other days of the study. We found a highly significant $(P<0.001)$ improvement in cough during the whole observational period from day 2 to day 28 , both in children treated with syrup alone and in those treated with syrup plus antibiotics, with a non-significant difference in progressive reduction of cough severity between the two groups (Table 2).

\section{Cough resolution}

The analysis of patients presenting cough (i.e., VCD score greater than 1) on each day of the study is reported in Fig. 2. Cough resolution began on Day 4 (8.7 \% in Group 1 and $5.1 \%$ in Group 2) and continued progressively through the entire study period. In particular, after the first week (Day 8) cough was completely resolved in more than one-half of patients in both groups (58.7\% in Group 1 and $53.8 \%$ in Group 2), while $22 \%$ of patients in Group 1 and 17.9 \% of patients in Group 2 were still coughing at Day 21. Cough was still reported in 8 patients of Group $1(17.4 \%)$ and in 5 patients of Group $2(12.8 \%)$ at the end of the observation, although the cough in those patients did not interfere with daily activities and sleep (i.e., VCD score equal to 2 or 3 ).

\section{Safety}

We observed a total of 11 adverse events with a significantly $(P=0.020)$ higher frequency in patients who received syrup plus antibiotic treatment than in those who took syrup alone. In fact, two patients in Group 1 $(4.3 \%)$ reported insomnia $(\mathrm{n}=1)$ and vomit $(\mathrm{n}=1)$ while nine patients in Group 2 (23.1\%) reported diarrhea $(\mathrm{n}=4)$, vomit $(\mathrm{n}=3)$ and skin $\operatorname{rash}(\mathrm{n}=2)$.

\section{Discussion}

Our group recently published a controlled randomized trial demonstrating the favorable effect of a homeopathic syrup on the resolution of acute cough in adults compared to placebo. [17]. Our data suggest an antitussive efficacy of this homeopathic syrup in children since the time-courses of the VCD severity score in the syrup treated children of this study resulted overlapping to that obtained in syrup treated adults in a randomized, double-blind placebo-controlled trail [17]. In fact, after 4 days the mean
Table 2 Improvement of cough during the whole observational period in children affected by wet acute cough caused by non-complicated URTI

\begin{tabular}{|c|c|c|c|}
\hline $\begin{array}{l}\text { Day from the start } \\
\text { of treatment }\end{array}$ & $\begin{array}{l}\text { Group 1: Homeopathic } \\
\text { syrup alone }(n=46)\end{array}$ & $\begin{array}{l}\text { Group 2: Homeopathic } \\
\text { syrup plus antibiotic } \\
\text { treatment }(n=39)\end{array}$ & $P$ value ${ }^{a}$ \\
\hline 2 & $-0.52 \pm 0.66$ & $-0.56 \pm 0.55$ & 0.673 \\
\hline 3 & $-1.02 \pm 0.75$ & $-0.97 \pm 0.74$ & 0.830 \\
\hline 4 & $-1.50 \pm 0.84$ & $-1.51 \pm 0.68$ & 0.833 \\
\hline 5 & $-1.93 \pm 0.88$ & $-1.92 \pm 0.96$ & 0.881 \\
\hline 6 & $-2.22 \pm 0.99$ & $-2.23 \pm 1.01$ & 0.814 \\
\hline 7 & $-2.46 \pm 0.98$ & $-2.41 \pm 1.29$ & 0.839 \\
\hline 8 & $-2.65 \pm 0.87$ & $-2.62 \pm 1.09$ & 0.837 \\
\hline 9 & $-2.76 \pm 0.87$ & $-2.79 \pm 1.03$ & 0.850 \\
\hline 10 & $-2.87 \pm 0.88$ & $-2.79 \pm 1.00$ & 0.723 \\
\hline 11 & $-2.83 \pm 1.00$ & $-2.82 \pm 1.00$ & 0.888 \\
\hline 12 & $-2.85 \pm 0.99$ & $-2.90 \pm 0.94$ & 0.880 \\
\hline 13 & $-2.91 \pm 0.96$ & $-3.00 \pm 0.92$ & 0.826 \\
\hline 14 & $-3.11 \pm 0.99$ & $-3.10 \pm 0.99$ & 0.945 \\
\hline 15 & $-3.20 \pm 1.02$ & $-3.15 \pm 1.01$ & 0.842 \\
\hline 16 & $-3.17 \pm 1.10$ & $-3.26 \pm 0.99$ & 0.725 \\
\hline 17 & $-3.26 \pm 1.08$ & $-3.26 \pm 0.94$ & 0.911 \\
\hline 18 & $-3.24 \pm 1.06$ & $-3.28 \pm 0.86$ & 0.911 \\
\hline 19 & $-3.37 \pm 1.02$ & $-3.33 \pm 0.90$ & 0.739 \\
\hline 20 & $-3.35 \pm 1.04$ & $-3.36 \pm 0.90$ & 0.993 \\
\hline 21 & $-3.43 \pm 1.00$ & $-3.36 \pm 0.90$ & 0.737 \\
\hline 22 & $-3.46 \pm 1.00$ & $-3.41 \pm 0.91$ & 0.867 \\
\hline 23 & $-3.48 \pm 1.03$ & $-3.38 \pm 0.96$ & 0.649 \\
\hline 24 & $-3.52 \pm 0.98$ & $-3.44 \pm 0.94$ & 0.675 \\
\hline 25 & $-3.52 \pm 0.98$ & $-3.49 \pm 0.91$ & 0.866 \\
\hline 26 & $-3.52 \pm 0.98$ & $-3.49 \pm 0.91$ & 0.866 \\
\hline 27 & $-3.46 \pm 1.00$ & $-3.46 \pm 0.94$ & 0.930 \\
\hline 28 & $-3.43 \pm 1.03$ & $-3.46 \pm 0.94$ & 0.867 \\
\hline
\end{tabular}

The mean ( \pm standard deviation) values of the reported changes in the verbal category-descriptive (VCD) scale versus the basal ones (Day 1) are shown. All changes in both groups were highly significant $(P<0.001$; Wilcoxon matched-pairs signed-rank test)

${ }^{\text {a}}$ Kruskal-Wallis test

VCD score was a bit more than 2 both in children (present study) and in adults [17] versus a mean VDC score of more than 3 observed in adults treated with placebo [17].

The data of the present study also indicate that adding antimicrobial agents to the homeopathic syrup does not in any way benefit the symptomatic treatment-so adding to the weight of evidence against prescribing antibiotics to patients with acute cough due to uncomplicated URTI. The differences in VCD scale between the homeopathic syrup group and the group that also received antibiotics are not statistically significant on any observation day, and the cough resolution trend was comparable week after week for both groups (Table 2). 


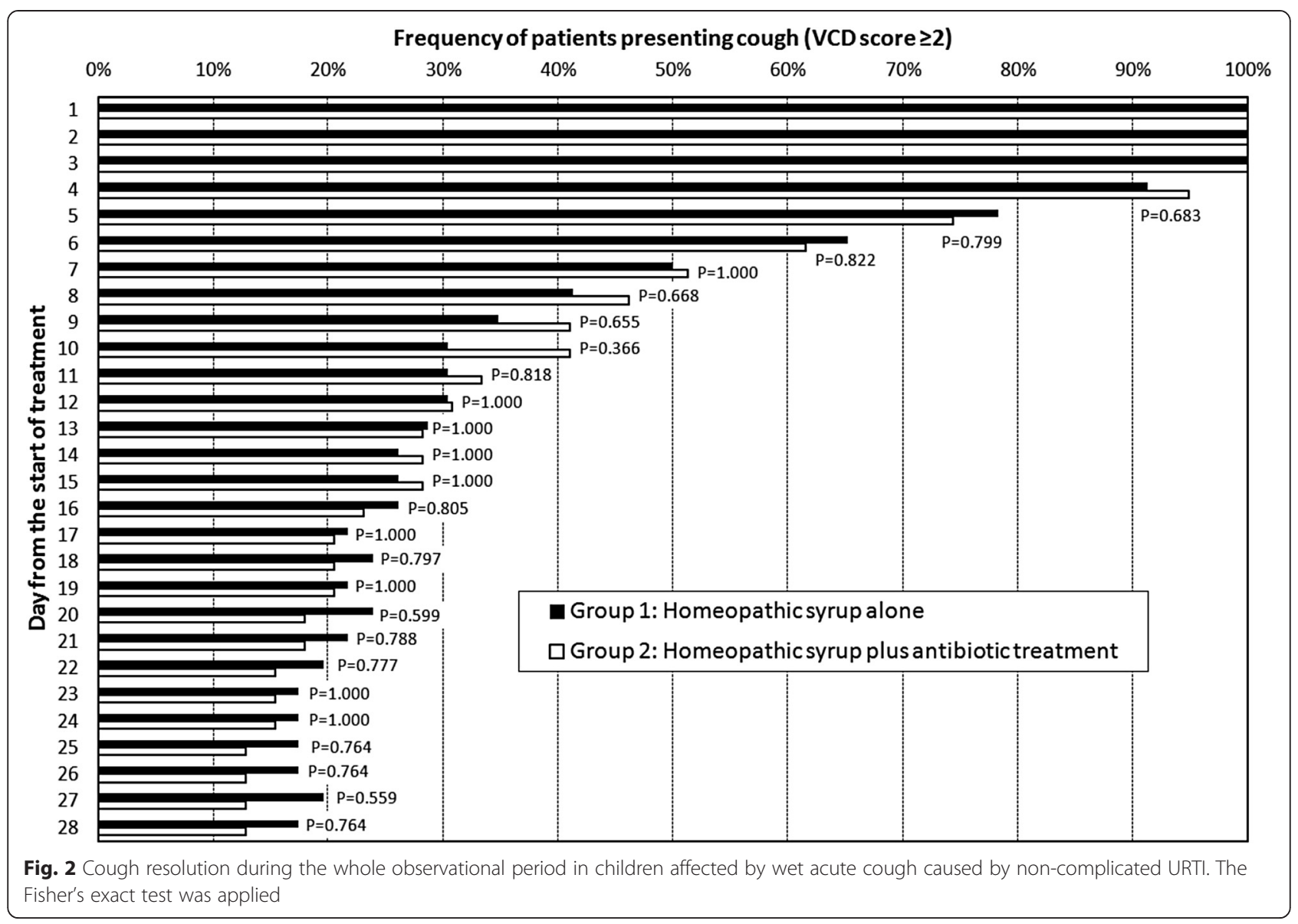

At the end of the second week of observation, cough was resolved in $74 \%$ of children treated with syrup alone and in $72 \%$ of children who received syrup plus antibiotic, while at the end of the 28-day observation period about $10-20 \%$ of children still presented cough, without any significant difference between the two treatment groups. These data are consistent with a recent review on the duration of symptoms of respiratory tract infections in children [3]. The percentage of children still presenting cough at the end of the study confirms that acute cough associated with URTI continues for several weeks, thus suggesting that it is necessary to educate people and the medical community about this natural history.

For the assessment of cough severity we did not use a complete parent-compiled quality of life quality (PC-QoL) questionnaire but instead we adopted a subjective verbal category-descriptive (VCD) scale [18]. Although this scale was validated against an objective cough meter measure in children slightly older (6-17 year-old) than our population (4-15 year-old), it can be considered reliable also for our study since it is a parent-assisted card. The VCD was found to be easier to use than the PC-QoL and so assures better compliance; in fact, we have made a preliminary test on the correct compilation of the VCD scale and the PC-QoL questionnaire, conducted on 20 patients for 28 consecutive days, and we obtained a compliance of $95 \%$ for VCD but just $35 \%$ for PC-QoL. It should also be pointed out that VCD has been proven to have a high correlation with domain variations of the PC-QoL questionnaire in children [21, 22]. Furthermore, since the VCD scale was used in our previous study on the same homeopathic syrup in adults, applying the same validated assessment tool in this study on a child population enabled us to obtain standardized and comparable data between children and adults [17].

As far as safety is concerned, it is worth noting that a significant difference was found between the two groups of children: only two children in the group treated with syrup alone reported adverse effects, versus nine children in the group treated with the syrup plus antibiotics.

As far as the limitations of the research are concerned, a major weakness of our study arises from the observational design that we applied in this appraisal. Thus we did not considered a placebo group since the main goal of our research was not the effectiveness of homeopatic syrup but it was to evaluate the role of additional antibiotic. It should be pointed out that this research was a 
pilot study conducted before starting a larger trial on the role of antitussive and mucolytic drugs in children; however, the results of this preliminary study can provide valuable information for the sizing of future rigorous controlled studies, to be planned with a random allocation of patients to study groups.

\section{Conclusion}

In conclusion, our data confirm that the studied homeopathic treatment has potential benefits on cough in children, as well as highlighting the good safety profile of this treatment. Supplementing the syrup with antibiotics did not improve cough resolution and was associated with more adverse events than the homeopathic syrup alone. These results indicate that antibiotics should not be routinely prescribed for uncomplicated acute cough secondary to URTI, as they are inappropriate for this condition and might be even dangerous- leading to increased antimicrobial resistances and adverse events, without evidence of benefit [23-27].

\section{Abbreviations}

PC-QoL: Parent-compiled quality of life; URTI: Upper respiratory tract infection; VCD: Verbal category-descriptive.

\section{Competing interests}

The authors declare that they have no competing interests.

\section{Authors' contributions}

AZ contributed to conception, design and interpretation of data, as well as in drafting and revising the manuscript. SC supported the pediatric practitioners in the management of patients and in drafting the manuscript. MM made the acquisition of data and supported the pediatric practitioners in themanagement of patients. CMSI made the acquisition of data and supported the pediatric practitioners in the management of patients. MM contributed to the interpretation of data, helped to draft the manuscript and revised the manuscript critically. EN performed the statistical analysis. AMML contributed to the design, analysis and interpretation of data, as well as in drafting and revising the manuscript. All authors read and approved the final manuscript.

\section{Acknowledgements}

We thank Boiron SA, Messimy, France for a non-binding financial contribution.

\section{Author details}

${ }^{1}$ Italian Association for Cough Study (AIST), Via Mazzini, 12, 40138 Bologna, Italy. ${ }^{2}$ Department of Pediatrics, Alma Mater Studiorum - University of Bologna, Bologna, Italy. ${ }^{3}$ Respiratory Medicine and Intensive Care Unit, Sant'Orsola Malpighi Hospital, Alma Mater Studiorum - University of Bologna, Bologna, Italy. ${ }^{4}$ Department of Medical and Surgical Sciences, Alma Mater Studiorum - University of Bologna, Bologna, Italy.

Received: 18 June 2015 Accepted: 27 July 2015

Published online: 07 August 2015

\section{References}

1. Chonmaitree T, Revai K, Grady JJ, Clos A, Patel JA, Nair S, et al. Viral upper respiratory tract infection and otitis media complication in young children. Clin Infect Dis. 2008;46(6):815-23.

2. Worrall G. Acute cough in children. Can Fam Physician. 2011;57(3):315-8.

3. Thompson M, Vodicka TA, Blair PS, Buckley DI, Heneghan C, Hay AD, et al. Duration of symptoms of respiratory tract infections in children: systematic review. BMJ. 2013;347(Dec11 1):f7027.

4. Shields MD, Thavagnanam S. The difficult coughing child: prolonged acute cough in children. Cough. 2013;9(1):11.
5. Hay AD, Heron J, Ness A. The prevalence of symptoms and consultations in pre-school children in the Avon Longitudinal Study of Parents and Children (ALSPAC): a prospective cohort study. Fam Pract. 2005;22(4):367-74.

6. Leonardi GS, Houthuijs D, Nikiforov B, Volf J, Rudnai P, Zejda J, et al. Respiratory symptoms, bronchitis and asthma in children of Central and Eastern Europe. Eur Respir J. 2002;20(4):890-8.

7. Smith SM, Schroeder K, Fahey T. Over-the-counter (OTC) medications for acute cough in children and adults in community settings. Cochrane Database Syst Rev. 2014;11:CD001831.

8. Blasio FD, Dicpinigaitis PV, Rubin BK, Danieli GD, Lanata L, Zanasi A. An observational study on cough in children: epidemiology, impact on quality of sleep and treatment outcome. Cough. 2012;8(1):1.1.

9. Vernacchio L, Kelly JP, Kaufman DW, Mitchell AA. Cough and cold medication use by US children, 1999-2006: Results from the Slone Survey. Pediatrics. 2008;122(2):e323-9.1.

10. Grijalva CG, Nuorti JP, Griffin MR. Antibiotic prescription rates for acute respiratory tract infections in US ambulatory settings. JAMA. 2009;302(7):758-66.

11. André M, Schwan $\AA$, Odenholt I. Upper respiratory tract infections in general practice: diagnosis, antibiotic prescribing, duration of symptoms and use of diagnostic tests. Scand J Infect Dis. 2002;34(12):880-6.

12. Whaley LE, Businger AC, Dempsey PP, Linder JA. Visit complexity, diagnostic uncertainty, and antibiotic prescribing for acute cough in primary care: a retrospective study. BMC Fam Pract. 2013;14(1):120.

13. Panagakou SG, Spyridis N, Papaevangelou V, Theodoridou KM, Goutziana GP, Theodoridou MN, et al. Antibiotic use for upper respiratory tract infections in children: a cross-sectional survey of knowledge, attitudes, and practices (KAP) of parents in Greece. BMC Pediatr. 2011;11:60.

14. Nyquist AC, Gonzales R, Steiner JF, Sande MA. Antibiotic prescribing for children with colds, upper respiratory tract infections, and bronchitis. JAMA. 1998;279(11):875-7.

15. Arroll B, Kenealy T. Antibiotics for the common cold, a meta-analysis. Cochrane Database Syst Rev. 2000;2:CD000247.

16. Hay AD, Wilson A, Fahey $T$, Peters TJ. The duration of acute cough in pre-school children presenting to primary care: a prospective cohort study. Fam Pract. 2003;20(6):696-705.

17. Zanasi A, Mazzolini M, Tursi F, Morselli-Labate AM, Paccapelo A, Lecchi M. Homeopathic medicine for acute cough in upper respiratory tract infections and acute bronchitis: A randomized, double-blind, placebo-controlled trial. Pulm Pharmacol Ther. 2014;27(1):102-8.

18. Chang AB, Newman RG, Carlin JB, Phelan PD, Robertson CF. Subjective scoring of cough in children: parent-completed vs child-completed diary cards vs an objective method. Eur Respir J. 1998;11(2):462-6.

19. Dupont WD, Plummer WD. Power and sample size calculations: a review and computer program. Control Clin Trials. 1990;11:116-28.

20. Dupont WD, Plummer WD. Power and sample size calculations for studies involving linear regression. Control Clin Trials. 1998;19:589-601.

21. Newcombe PA, Sheffield JK, Chang AB. Minimally important change in a parent-proxy quality-of-life questionnaire for pediatric chronic cough. Chest. 2011;139(3):576-80.

22. Schmit KM, Coeytaux RR, Goode AP, McCrory DC, Yancy J, William S, et al. Evaluating cough assessment tools: a systematic review. Chest. 2013;144(6):1819-26.

23. Kenealy T, Arroll B. Antibiotics for the common cold and acute purulent rhinitis. Cochrane Database Syst Rev. 2013;6:CD000247.

24. Zoorob R, Sidani MA, Fremont RD, Kihlberg C. Antibiotic use in acute upper respiratory tract infections. Am Fam Physician. 2012;86(9):817-22.

25. Spurling GKP, Del Mar CB, Dooley L, Foxlee R. Delayed antibiotics for respiratory infections. Cochrane Database Syst Rev. 2007;3:CD004417.

26. Cunha BA. Therapeutic implications of antibacterial resistance in communityacquired respiratory tract infections in children. Infection. 2004;32(2):98-108.

27. Goossens H. Antibiotic consumption and link to resistance. Clin Microbiol Infect. 2009;15 Suppl 3:12-5. 